\title{
Is the Welfare State Relevant for Economic Growth? Evidence for Portugal
}

\author{
Pedro Bação ${ }^{1} \cdot$ Marta Simões $^{1}$ (D)
}

Published online: 13 July 2020

(c) Association for Comparative Economic Studies 2020

\begin{abstract}
In this paper, we describe the evolution of welfare state spending in Portugal in the period 1980-2018 and consider its implications for economic growth. Overall, welfare spending in Portugal increased over this period as a percentage of GDP, but stagnated or even declined in recent years. Our empirical analysis attempts to quantify the contribution of welfare spending to economic growth in that period. We provide a comprehensive robustness check by means of specification-curve analysis. We conclude that the sign of the effect varies with the specification choices, but neither positive nor negative estimates are robust.
\end{abstract}

Keywords Welfare state $\cdot$ Social spending $\cdot$ Economic growth $\cdot$ Portugal $\cdot$ VAR model $\cdot$ Specification-curve analysis

JEL Classiication $\mathrm{C} 22 \cdot \mathrm{I} 38 \cdot \mathrm{O} 11 \cdot \mathrm{O} 52$

\section{Introduction}

The welfare state is a rather recent institution in Portugal. The current welfare system is a result of the 1974 political revolution and the first steps taken by the democratic regime, which were marked by the creation of the National Health System (NHS), the expansion of the public education system and the introduction of a public social security system for all citizens (Carolo and Pereirinha 2010). However, the 2007-2008 financial crisis and the ensuing sovereign debt crisis reduced the fiscal capacity to provide a modern and effective welfare state (Gonzalez and Figueiredo 2015), raising fears that this retrenchment may hamper growth.

Marta Simões

mcsimoes@fe.uc.pt

Pedro Bação

pmab@fe.uc.pt

1 Univ Coimbra, CeBER, Fac Econ, Av. Dias da Silva 165, 3004-512 Coimbra, Portugal 
The main goals of the welfare state are to increase income equality and equality of opportunities (Nolan et al. 2012; Stiglitz 2018; Van Lancker and Van den Heede 2019). Income equality and equality of opportunities are sometimes cited as determinants of economic growth (Aghion et al. 1999; Dominicis et al. 2008; Cingano 2014). Thus, the welfare state may have the ability to influence economic growth (Atkinson 1996a) and, in turn, economic growth may help the welfare state pursue its objectives (Tridico and Paternesi Meloni 2018). The literature on the relationship between the welfare state and growth is however somewhat divided. Theoretical predictions point to two opposite sign effects of the welfare state on economic growth (Atkinson 1995; Lindert 2004; Piachaud 2013; Andersen 2015). A positive effect emerges when the welfare state creates the conditions for economic agents to make decisions that promote growth, such as investing in human capital or taking more risks associated with innovation. On the other hand, a negative effect arises due to the need to finance the welfare state through taxation, since this introduces distortions in economic decisions that are detrimental to growth, such as working less and with less effort and reducing savings and thus investment.

This paper investigates whether the welfare state impacts growth using 1980-2018 data for Portugal. The empirical approach makes use of a vector autoregression (VAR) model inspired by a Cobb-Douglas aggregate production function that includes physical and human capital stocks, total factor productivity and a measure of welfare state effort (social spending). Thus, we allow the influence of welfare spending on economic growth to occur through both factor accumulation and productivity. In addition, we allow for the possibility that the effects may differ across different components of social spending. This disaggregated analysis might have important implications for the design of more effective economic and social policies that result in a more inclusive society. Since the researcher has a number of degrees of freedom when setting up the empirical analysis (in this case based on a VAR model) and there seems to be a tendency to report only the desired (statistically significant) outcome, in this study we use specification-curve analysis to assess the robustness of the results. This technique involves running all the reasonable/relevant regressions and evaluating the results against a benchmark obtained by simulating the data under the null hypothesis of no effect (Simonsohn et al. 2015). We apply this analysis twice: one from the point of view of a researcher who finds a positive effect of welfare spending on economic growth, and the other from the point of view of an estimated negative effect. By considering not only total public social spending but also different types of social spending, we allow for the possibility that someone searching for an impact of the welfare state on growth might find one by changing the measure of social spending.

Our work differs and builds upon previous research in several ways. First, our focus is not exclusively on total public social spending, nor on particular components of social spending taken in isolation, as in Herce et al. (2001), Arjona et al. (2002), Baldacci et al. (2008), Afonso and Furceri (2010), Afonso and Alegre (2011), Im et al. (2011), Ormaechea and Morozumi (2013), Afonso and Jalles (2014) and many other examples can be found in the reviews of the literature by Awaworyi Churchill et al. (2017), Awaworyi Churchill and Yew (2017) and Awaworyi Churchill et al. (2015). We want to deliver a more comprehensive picture of the possible relationship between the welfare state and economic growth by taking into account all the nine social policy 
areas identified in the OECD Social Expenditures database - old age, survivors, incapacity-related benefits, health, family, active labour market policies, unemployment, housing and other social policy areas (OECD 2019) — and integrating all of them in a procedure designed to investigate the robustness of the empirical results.

In fact, the main contribution of this paper is to propose an application of the novel technique of specification-curve analysis to the analysis of the impact of welfare spending on economic growth. To the best of our knowledge, this is the first application of this technique in economics. This technique provides a framework for dealing with possible data mining and specification searches that hamper the robustness and credibility of the reported findings. We borrow it from empirical studies in the field of psychology-e.g. Rohrer et al. (2017), Rohrer (2018), Bryan et al. (2019), Orben and Przybylski (2019), Voracek et al. (2019) and Frey et al. (2020).

We centre our analysis on a single country (Portugal), which in recent decades has been through important challenges, as described in section "The Portuguese Context: Some Facts and Figures". Therefore, we do not expect our conclusions to generalize easily to other countries. One of the causes for the varied results identified in the meta-regression analyses on the relationship between specific components of social expenditure and economic growth by Awaworyi Churchill et al. (2017), Awaworyi Churchill and Yew (2017) and Awaworyi Churchill et al. (2015) is precisely the different country samples under analysis. This is also in line with the recommendations of the literature on welfare state regimes and social and economic outcomes that contends that the relationship might be contingent upon differences in arrangements regarding welfare institutions. Several types of welfare states coexist, differing in their historical evolution, organization and reach, among other features (Esping-Andersen 1990; Hay and Wincott 2012) and previous studies have shown that these different models should be accounted for when investigating the relationship betwixt social spending and social and economic outcomes (e.g. Kammer et al. 2012; Bergqvist et al. 2013; Chauvel and Eyal Bar-Haim 2016; Toikko and Rantanen. 2017; Tridico and Paternesi Meloni 2018).

The paper is structured as follows. Section "The Portuguese Context: Some Facts and Figures" introduces the Portuguese case. Section "Controversies on the Relationship Between the Welfare State and Economic Growth: Theoretical Arguments and Recent Findings" briefly reviews the theoretical arguments and empirical literature that debate whether the welfare state is relevant for economic growth. The data and the empirical methods employed in this study are described in section "Empirical Modelling and Estimation Strategy". Section "Results" presents and discusses the findings of the empirical analyses. Section "Conclusion" offers concluding remarks.

\section{The Portuguese Context: Some Facts and Figures}

The period under analysis in this study, 1980-2018, coincides with the early years and deepening of the Portuguese European integration process. Just before, Portugal had gone through a political revolution (in 1974) and was taking the first steps as a democracy after 48 years of dictatorship. By joining the European Economic Community in 1986 (Portugal applied to become a member in as early as 1977), Portugal 
Fig. 1 Public social expenditure as a percentage of GDP, total and by category, Portugal 1980-2018. Notes: Total public social expenditure does not include education. Social expenditure on housing is not included due to the low ratios recorded, ranging from a minimum of $0 \%$ to a maximum of $0.006 \%$. "ALMP": Active Labour Market Policies. Source: OECD Social Expenditures database

became officially committed to the European integration process, important in supporting the transition to a developed democracy and achieving higher standards of living. European integration resulted also in the adoption of policy measures aimed at promoting convergence to the European Social Model (Carolo and Pereirinha 2010).

We begin by examining some quantitative information about the two main dimensions under analysis, welfare state effort and output. The quantitative assessment of welfare state expansion relies on social expenditures data. We use data from the OECD Social Expenditures database (SOCX) concerning public spending as a percentage of GDP, total and by social policy areas—old age, survivors, incapacityrelated benefits, health, family, active labour market policies, unemployment, housing and other social policy areas. Spending on education as a percentage of GDP (SE.XPD.TOTL.GD.ZS) is from the World Development Indicators of the World Bank (WDI). Annual output data were obtained from the European Commission Annual Macroeconomic database (AMECO) and refers to Gross Domestic Product at 2010 reference levels per head of population (RVGPD) in 1000 euros.

Figure 1 contains data for public social expenditure as a percentage of GDP, total and by spending categories, from the SOCX database and the WDI for Portugal over the period 1980-2018, whenever data are available. For the whole period, old age pensions, health and education expenditures are the most important components of social expenditure in terms of GDP $(12.6 \%, 5.9 \%$ and $4.9 \%$, respectively, in 2015), while housing, other social policy areas and active labour market policies are the least important ones $(0.003 \%, 0.17 \%$ and $0.55 \%$, respectively, in 2015$)$. As far as total public social expenditure as a percentage of GDP is concerned, from 1980 until 1986 spending ratios are relatively stable starting at $9.5 \%$ in 1980 and standing at $10.4 \%$ in 1986. According to Carolo and Pereirinha (2010), this sub-period belongs to what they identify as the second phase in the process leading up to the current welfare state system in Portugal. This second phase goes from 1974 until the mid-80s, a period when Portugal introduced a social security system for all citizens, including those that had not paid any contributions. From 1986 onwards (the third phase of the Portuguese welfare system according to Carolo and Pereirinha 2010, whose data ends in 2003), until around the year 2009, spending ratios record a clear and steady increase with total spending reaching $24.5 \%$ of GDP in 2009 . The period of the Great Recession (2007-2008), sovereign debt crisis (2011) and bailout of the Portuguese economy (2011-2014) coincides with stagnation and even decline in total spending as a percentage of GDP, as well as for most spending categories with the exception of old age pensions and unemployment benefits. ${ }^{1}$ The recovery of the Portuguese economy,

\footnotetext{
1 Voyvoda and Yeldan (2005) use an overlapping-generations model to analyse an earlier IMF-led intervention of a similar nature in Turkey. They argue that this intervention distorted welfare policies with harmful consequences for human capital accumulation.
} 

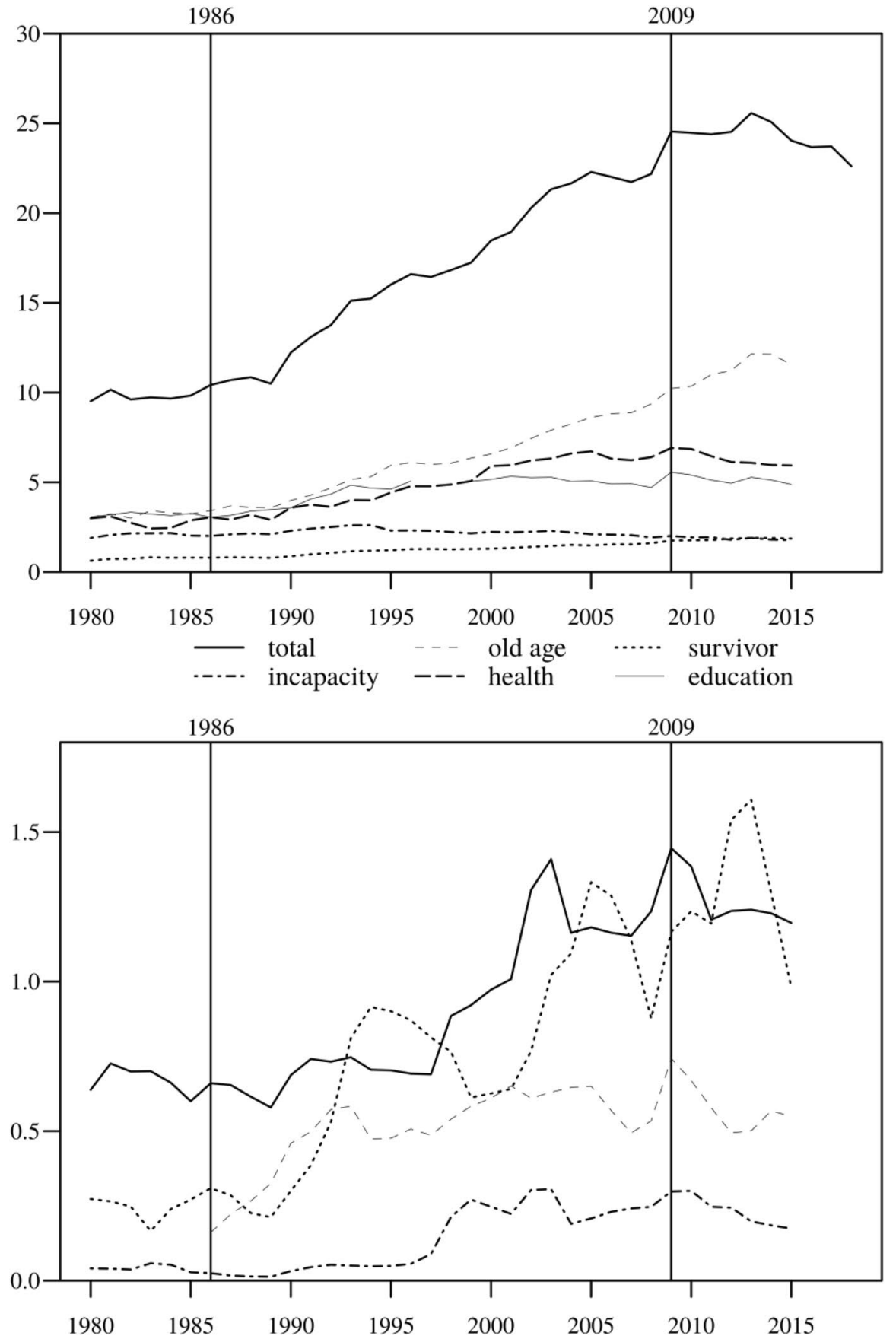

— family -.- ALMP $\cdots . . . \cdot$ unemployment $\quad . . \cdot$ other 
from 2014 onwards, has not been accompanied by an inversion of the previous negative trend in social expenditure as a percentage of GDP. In 2018, total spending stood at $22.6 \%$ of GDP, only slightly higher than in 2008 when it reached $22.2 \%$.

The 1980s were also a period of great expectations at the economic level. Accession to the EU was accompanied by a growth acceleration of the Portuguese economy relative to the previous decade, 1974-1985. During this earlier period, of political turmoil and concomitant economic hardships, the Portuguese economy became almost stagnant and balance of payments crises required two IMF interventions, in 1978-1979 and again in 1983-1985. The first years of European integration were quite favourable for Portugal in terms of output growth and thus created the conditions for political support to joining the Economic and Monetary Union. This became effective as of 1 January 1999, after a decade of preparations. Portugal experienced rapid economic growth in the years that preceded the launch of the euro (between 1995 and 1999-2000). Since then, however, the Portuguese economy experienced a very sluggish rate of economic growth, a scenario aggravated by the 2007-2008 financial crisis but foremost by the subsequent sovereign debt crisis. This crisis resulted in the third IMF bailout (this time joined by the ECB and the European Commission) that lasted from May 2011 until June 2014, albeit by mid2013 the Portuguese economy initiated a gradual recovery. This recent evolution of the Portuguese economy has been strongly affected by the austerity policies recommended by the Troika (IMF, ECB and European Commission) due to the need to reduce the deficit and public debt. This in turn has brought the welfare state to the forefront of the debate on Government retrenchment. At a time of unprecedented unemployment rates, access to unemployment insurance was restricted, resulting in a strong reduction in the number of the unemployed that could claim unemployment benefits. At that same time there were important restrictions in the access to a modern and effective national health system, increases in the number of students per teacher, changes in the criteria to claim family allowances, among others (Gonzalez and Figueiredo 2015). ${ }^{2}$

Figure 2 presents data on real GDP per capita, levels and growth rates, for Portugal over the period 1980-2018. Over this period, real GDP per capita recorded an average annual growth rate of $1.9 \%$, but with quite different performances throughout the period. Immediately before accession to the EU (1980-1985), income levels remained basically the same with real GDP per capita growing on average $0.6 \%$ a year. In the 5 years that followed (1985-1990) this growth rate increased by a factor of ten, slowed down to $1.8 \%$ in the $1990-1995$ period and again picked up to $3.5 \%$ a year over the next 5 years, 1995-2000. Over the course of the new millennium, stagnation was the dominant feature in terms of real GDP per capita, with the growth rate ranging from $-0.5 \%$ to $+0.5 \%$ during the three 5 years sub-periods from 2000 until 2015. In the last three years of the analysis, 2015-2018, however, real GDP

\footnotetext{
${ }^{2}$ Nevertheless, note that Caminada et al. (2019) argue that, in the period after the Great Recession, fiscal policies associated with welfare provision were still effective in reducing income inequality, namely through pensions. For a more general view of inequality and financial globalization, see Furceri et al. (2020).
} 


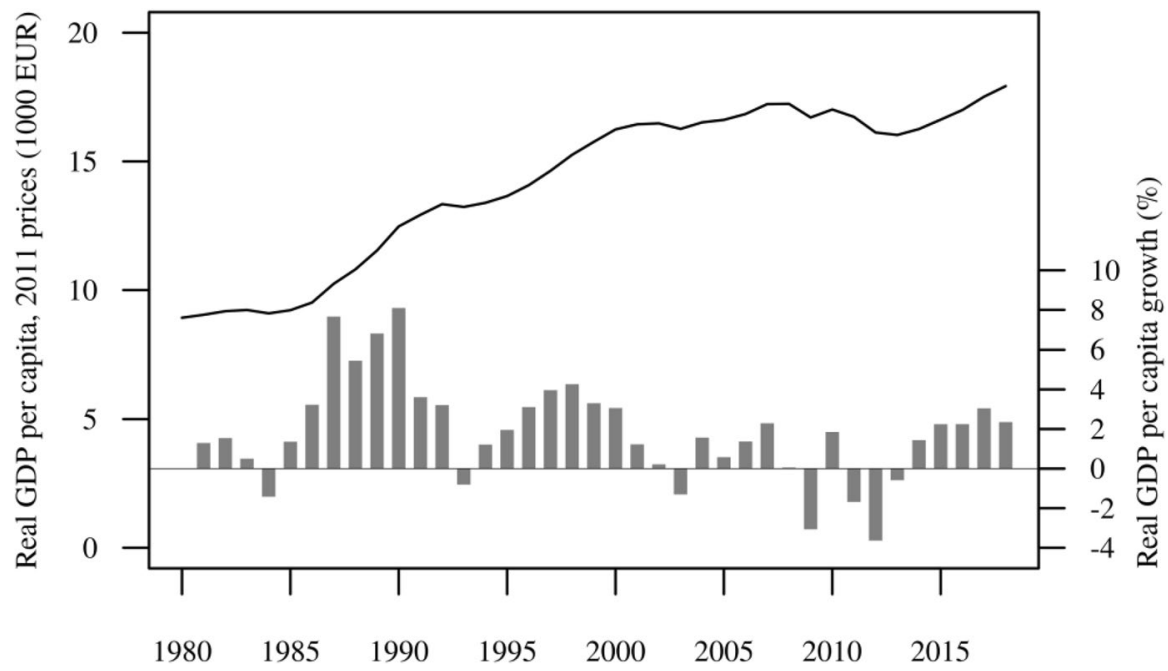

Fig. 2 Real GDP per capita, levels and growth rates, Portugal 1980-2018. Source: AMECO database, May 2019 release

per capita grew at an annual average growth rate of $2.5 \%$ and in 2017 real GDP per capita surpassed the pre-crisis level.

In late 2015, a new government resulting from an understanding between leftwing parties replaced the government that had been responsible for the implementation of the economic and financial assistance programme. The new government introduced some changes in spending and in the structure of the Portuguese welfare system, but a fundamental question arises. Will the rescaling and reorganization of the Portuguese welfare system aggravate further the already dismal long-run growth prospects in a country that ranks as one of the most unequal in Europe and presents still relatively low educational attainment levels?

From the perspective of social cohesion, Table 1 presents data on selected social indicators for Portugal for some of the years covered in this study $(1980,1990$, 2000,2010 and 2018) in order to provide an idea of the dynamics of this dimension in Portugal. We also undertake a comparative analysis of the performance of Portugal. Our reference is the aggregate which comprises the 28 member countries of the European Union (EU), known as the EU-28. The main message from these data is that progress has been modest when one considers the expected outcomes from the expansion of the welfare state in Portugal in terms of income distribution and the poverty rate: the Gini index of income distribution remained basically unchanged $(1980-33.5 ; 2018-33.7)$, the at-risk-of-poverty rate recorded a slight reduction $(2000-21 \% ; 2018-17.3 \%)$ and the top $10 \%$ income share rose from $30.05 \%$ in 1980 to $37.1 \%$ in 2018 . In summary, poverty and inequality remain high and these standard indicators of income inequality and poverty are consistently higher in Portugal than in the EU-28. On the other hand, until 2010 improvements in the health status of the population have been quite substantial, due to the national health system created in 1979 , which is presently considered at risk on 


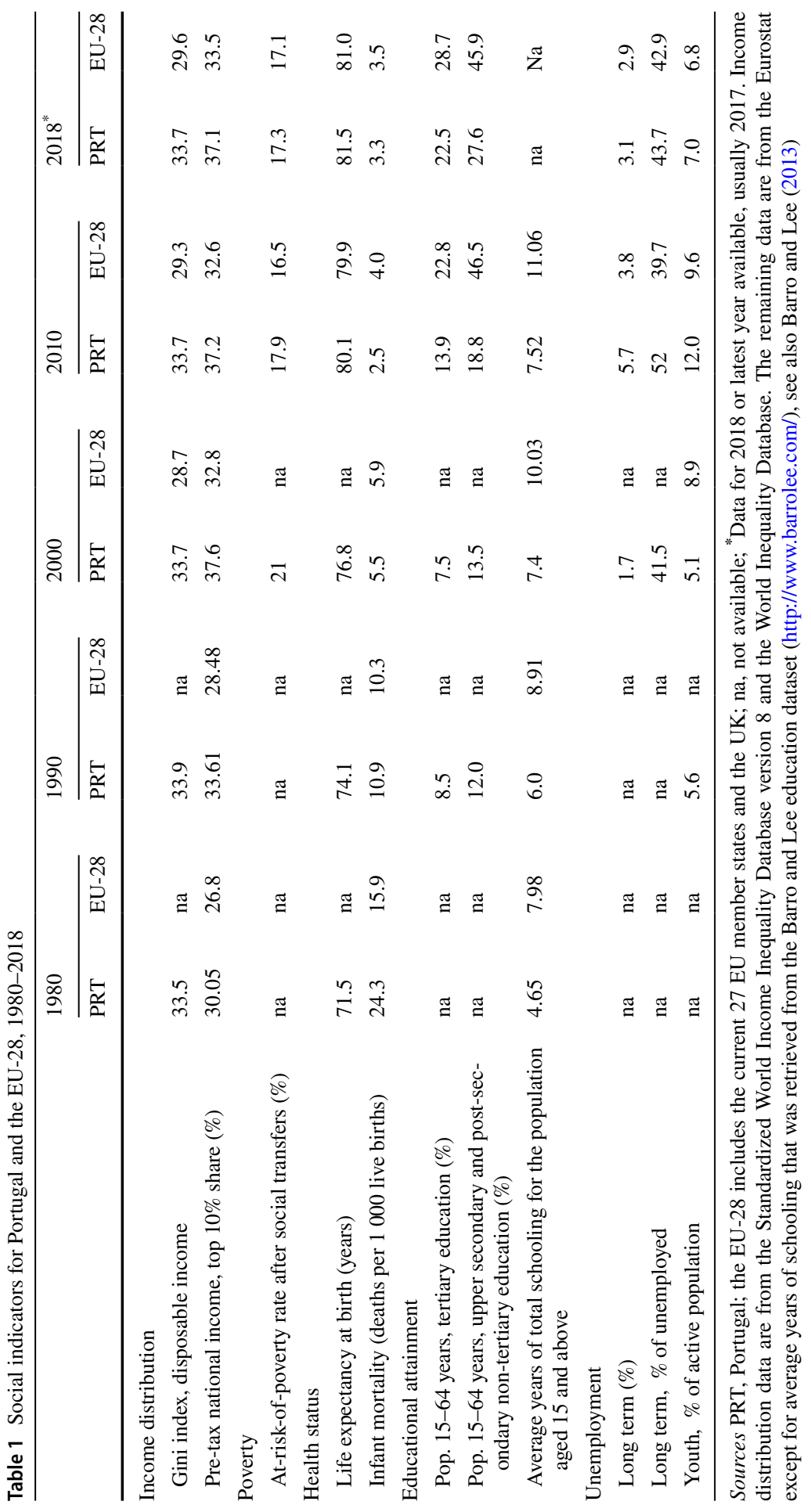


account of under-investment (Gonzalez and Figueiredo 2015). From 1980 until 2010 , life expectancy at birth increased from 71.5 to 81.5 years and infant mortality decreased from 24.3 deaths per 1000 live births to 2.5, although in 2018 it stood at 3.3. Additionally, from the 2000s onwards Portugal fares better than the EU-28 in both health status indicators. Education is another major area of state intervention in Portugal, but one where the accomplishments are less striking. The increase in public education expenditure has contributed to higher educational attainment levels of the Portuguese population, with average years of schooling increasing from 4.65 years in 1980 to 7.52 years in 2010 . Nevertheless, in 2018 , only around $50 \%$ of the population aged 15-64 years had completed upper secondary, post-secondary and tertiary education. Despite the improvements, when compared to the EU-28 Portugal still presents relatively low educational attainment levels. For example, in 2018, the percentage of the population aged 15-64 years with upper secondary and post-secondary non-tertiary education and tertiary education amounted to $75 \%$ in the EU-28 and only 50\% in Portugal. Another area of concern is that of long-term unemployment and youth unemployment. Although unemployment for most of the period has been quite low, it started to climb in the mid-2000s and this rise was accompanied by an increase in both the long-term and the youth unemployment rates. In 2018, long-term unemployment represented almost $43.7 \%$ of the unemployed and the youth unemployment rate was $7 \%$. Relative to the EU-28, the numbers are not strikingly different, although Portugal consistently records slightly higher values.

\section{Controversies on the Relationship Between the Welfare State and Economic Growth: Theoretical Arguments and Recent Findings}

Economic growth, the steady increase in output in the long run, is the immediate result of either higher accumulation of factors of production or improvements in efficiency/productivity of those factors, or, more realistically, both. These direct sources of growth are in turn determined by more fundamental sources, i.e. those features that have an important influence on a country's ability to accumulate inputs and become more productive and efficient, such as the institutional arrangements that frame economic activity (Hall and Jones 1999; Rodrik 2003). Unlike the proximate determinants of growth, there is no consensus as to the fundamental sources of growth, an issue also known as open-endedness of growth theory, implying that different growth factors highlighted by different theories are compatible with one another (Brock and Durlauf 2001). The welfare state comes under the classification of fundamental sources, in particular institutions. However, both at the theoretical and at the empirical level, the studies that investigate the impact of the welfare state on economic growth have reached no definite conclusions on the sign, transmission mechanisms and direction of causality of the relationship.

The literature suggests that the welfare state affects aggregate output behaviour, but there is no consensus as to the sign of this effect (Atkinson 1995; Lindert 2004; Piachaud 2013; Andersen 2015). Critics of welfare intervention by the state pose that the financing side of welfare provision introduces distortions in economic decisions 
that are detrimental to growth. The traditional view is that the taxes needed to finance social expenditure sap economic efficiency and thus growth (Johansson et al. 2008; Acosta-Ormaechea and Yoo 2012; Johansson 2016; Prichard 2016; McNabb 2018). Taxes affect the behaviour of individuals because, for instance, the work-leisure and the consumption-savings decisions become different relative to a situation with no taxes. Higher income taxes encourage people to work less and spend more time in leisure (although this depends on the relative importance of substitution vs. income effects); thus, the total amount of output decreases. Through its impact on the fraction of income being saved, taxation influences capital accumulation and in this way growth. Higher income taxes lower the net returns from savings and, if savings rates are higher for richer individuals, a more progressive tax system has even more adverse effects on savings. Investment becomes lower than in the absence of taxes and, since there is less capital accumulation, a negative impact on economic growth emerges. Income taxes also lower the gains from education and result in less human capital accumulation, again hampering growth. Social contributions increase labour costs and in a context of economic globalization reduce competitiveness and growth (Pfaller 1987). But different financing mechanisms for supporting social protection systems might have different outcomes in terms of economic growth since some modes of financing are less distortionary than others. For instance, Arnold et al. (2011) conclude that corporate income taxes have the strongest negative effects on growth, followed by personal income taxes, while consumption taxes have less adverse effects, and finally property taxes appear to produce the least important effect.

The various ways the financial resources that support the welfare state are spent result in different channels of influence relative to economic growth (Acosta Ormaechea and Morozumi 2013; Fournier and Johansson 2016; Johansson 2016; Chu et al. 2018). A number of social policies have the potential to produce a positive growth effect. Education and health expenditure promote the accumulation of human capital, overcoming market failures that do not allow talented individuals to have access to education/healthcare, and thus enabling countries to fulfil their human capital potential and grow faster (Benos and Zotou 2014; Bloom et al. 2018). Family support schemes, such as childcare or long-term care programmes, prevent people from quitting their jobs (or encourage them to work) because they have to raise their children or take care of dependent family members, thus improving productivity and stimulating growth (Kim and Antonopoulos 2011; Zhang et al. 2017). Pension funds that manage pension contributions used to pay for pensions through the public pension system should invest the pool of funds in the interim period so that the earnings on the investments generate more income to pay for workers' retirement. Those investments will increase capital accumulation and promote faster growth (similar to the positive growth impact of private pension funds found by Bijlsma et al. 2018). Unemployment compensation can help unemployed people find a better job by enabling jobseekers to wait for a job that matches their skills, and may even constitute an incentive to invest in their human capital (Brown and Kaufold 1988). Overall, social transfers reduce income inequality, which according to some authors has a positive influence on growth (Galor and Moav 2004; Cingano 2014; Berg et al. 2018). The foregoing arguments support the view that the welfare state 
leads to improved macroeconomic performance in the long run in the form of faster growth (Andersen 2015). In summary, the sign of the impact of the welfare state on economic growth depends on how the financial resources that support the welfare state are spent (Arjona et al. 2002).

It is thus not surprising that empirical studies on the relationship between welfare state effort and economic growth are somewhat divided. This lack of consensus from the existing empirical studies is made clear by recent meta-regression analyses by Awaworyi Churchill and co-authors, in particular Awaworyi Churchill et al. (2017), Awaworyi Churchill and Yew (2017) and Awaworyi Churchill et al. (2015). These meta-regression analyses aim at synthesizing the evidence and accounting for the sources of heterogeneity among reported findings on the link between main components of social expenditure and economic growth. The main takeaway is that a deeper understanding of the welfare state-economic growth nexus demands disaggregating the former according to its different categories.

Awaworyi Churchill and Yew (2017) focus on 149 estimated coefficients for the relationship between government transfers (GTRAN) and growth, retrieved from 23 different studies. These government transfers refer to different types of social expenditure, in particular social security, pensions and unemployment benefits, not including education nor health. A first inspection of the retrieved coefficients leads the authors to conclude that the results vary quite a lot in terms of statistical significance and the quantitative importance of the effect. Many studies did not reject the null hypothesis of no impact and from the ones that did reject it there is no clear indication as to the sign of that impact. From the meta-regression analysis carried out the most important results for the purpose of our study are that for developed countries (the country group to which Portugal belongs to) the sign of the relationship is negative, although differences persist across social spending components. Unemployment benefits have a negative growth impact, but for social security transfers the effect is positive. Also, results with time series data lead to more intense negative effects and the opposite applies to the use of more recent data. Awaworyi Churchill et al. (2017) use 237 estimated coefficients from 29 selected empirical studies on the relationship between education expenditure and economic growth and conclude that for developed countries the relationship is positive and statistically significant. However, studies that use data from 1990 and beyond tend to report less positive effects of education expenditure on growth. Finally, Awaworyi Churchill et al. (2015) synthetize the evidence regarding the impact of health expenditures on economic growth based on the results from 12 studies with a total of 69 estimates, of which $37.58 \%$ are statistically insignificant, $56.52 \%$ are negative, and only four estimates $(5.80 \%)$ are positive. The meta-analysis indicates that there is a genuine negative effect of health expenditures on growth that is more adverse when the datasets used are older (end before the 2000s) and the samples consist of OECD countries only.

The opposing theoretical arguments on the impact of the welfare state on economic growth and the varied evidence thus claim for more empirical research on the subject, in particular country-specific analysis since it does not seem possible to derive one-size-fits-all policy implications given the variety of welfare state models adopted by different countries. As the results from meta-analysis studies show, 
it is important to control for the robustness of the results found. Since one possible source of the heterogeneity of the results found in previous studies concerns the options made by researchers in terms of processing the data, when different approaches to running the analysis can be justified, namely in what concerns the type of social spending used as a proxy for welfare state effort, we apply the specification-curve analysis proposed by Simonsohn et al. (2015) to mitigate this problem.

\section{Empirical Modelling and Estimation Strategy}

To determine the sign of the relationship between the welfare state and economic growth, it is common to use a reduced form equation that relates output growth to initial income per capita, a variable capturing the welfare state, and a vector of control variables. A common problem faced by empirical growth studies is that of model uncertainty due to the large number of features with the potential to influence economic growth; different empirical models lead to different conclusions concerning the same growth determinants (Rockey and Temple 2016). In order to overcome to some extent this problem, we investigate the impact of the welfare state on growth through the more consensual proximate determinants, factor accumulation and productivity. Therefore, the sign and magnitude of the welfare state growth impact is estimated through the use of a VAR model defined according to a standard Cobb-Douglas aggregate production function with human capital, such as the function presented in Hall and Jones (1999).

Hall and Jones (1999) assume that output, $Y$, is produced according to the following production function:

$$
Y_{t}=K_{t}^{\alpha}\left(A_{t} H_{t}\right)^{1-\alpha}
$$

where $K$ is the stock of physical capital, $H$ is the amount of human capital-augmented labour used in production, $A$ is total factor productivity, and $\alpha$ is the capital share.

Output per worker, $y$, can thus be written as:

$$
y_{t}=k_{t}^{\alpha}\left(A_{t} h_{t}\right)^{1-\alpha}
$$

where $k$ is the stock of physical capital per worker and $h$ is the amount of human capital per worker. Thus, Eq. (2) can be rewritten as:

$$
y_{t}=\left(K_{t} / Y_{t}\right)^{\alpha /(1-\alpha)} A_{t} h_{t}
$$

Taking logs and first differences of both sides yields:

$$
g_{t}^{y}=[\alpha /(1-\alpha)] g_{t}^{K / Y}+g_{t}^{A}+g_{t}^{h}
$$

where the g's are the log growth rates of the variables in superscript. From this point of view, what matters for GDP growth is the growth of productivity and of factor inputs (proximate sources of growth). Hall and Jones (1999) analyse the impact of 
social infrastructure on each of the terms (after taking logarithms) in Eq. (3). In that way they attempt to identify the channels through which social infrastructure may exert an impact on output per worker. Their approach is based on static cross-country regressions. Our approach is also based on the analysis of the relation between the welfare state and the proximate sources of growth. However, we resort to a VAR model where we include the growth rates of total factor productivity, the capital-output ratio and human capital-i.e. the terms in the RHS of Eq. (4)—alongside a variable related to welfare state effort. The growth rate of total factor productivity must be estimated; we do so by setting $\alpha$, the capital share, to one third, as is customary. To be specific, from Eq. (2), TFP (in logarithms) was computed as follows:

$$
\log \left(A_{t}\right)=[1 /(1-\alpha)] \log \left(y_{t}\right)-[\alpha /(1-\alpha)] \log \left(k_{t}\right)-\log \left(h_{t}\right) .
$$

The general form of the VAR model of order $p$ that we use to analyse the relationship between the welfare state and real GDP per worker growth can thus be written as:

$$
X_{t}=\beta_{0}+\beta_{1} X_{t-1}+\beta_{2} X_{t-2}+\cdots+\beta_{p} X_{t-p}+\varepsilon_{t}
$$

where the vector $\mathrm{X}$ contains the variables under analysis (the capital-output ratio, human capital, total factor productivity, all in log growth rates) and a measure of social expenditure. Details on the variables used and respective sources are provided in Table 2. Figures 3 and 4 show the behaviour of the aggregate production function variables in levels and in log growth rates, respectively. Given that our focus is not on the stochastic properties of the individual series per se (which the short span of our sample would cloud), but on the application of a novel approach to study the robustness of econometric analyses, we did not perform stationarity/unit root tests for the individual series. Note also that our measure of welfare spending is a measure of public social expenditure as a percentage of GDP. Ideally, one should employ a measure of spending shocks, perhaps constructed using a narrative approach as in Romer and Romer (2016). However, measures similar to ours are common in the related literature (e.g. Arjona et al. 2002; Baldacci et al. 2008; Afonso and Furceri 2010; Afonso and Alegre 2011; Afonso and Jalles 2014).

As discussed in section "The Portuguese Context: Some Facts and Figures", public expenditure associated with the notion of "welfare state" comprises many different elements. Different researchers (or the same researcher at different times) may want to analyse the relation between different components of welfare state expenditure and economic growth. In this context (although not in the case where the researcher wishes to study specific channels relating certain social spending categories and economic growth), one may say that researchers have a degree of freedom in the choice of the measure of the welfare state. However, there are many other choices to be made before finally getting and analysing the estimates of an econometric model such as that in Eq. (6). More immediate choices concern whether to take the logarithm of the measure of public expenditure and whether to use the level or the first difference of the series. Equation (6) hints at the existence of another degree of freedom: the number of lags in the VAR model (parameter $p$ ). Other choices may emerge as a result of the definition 


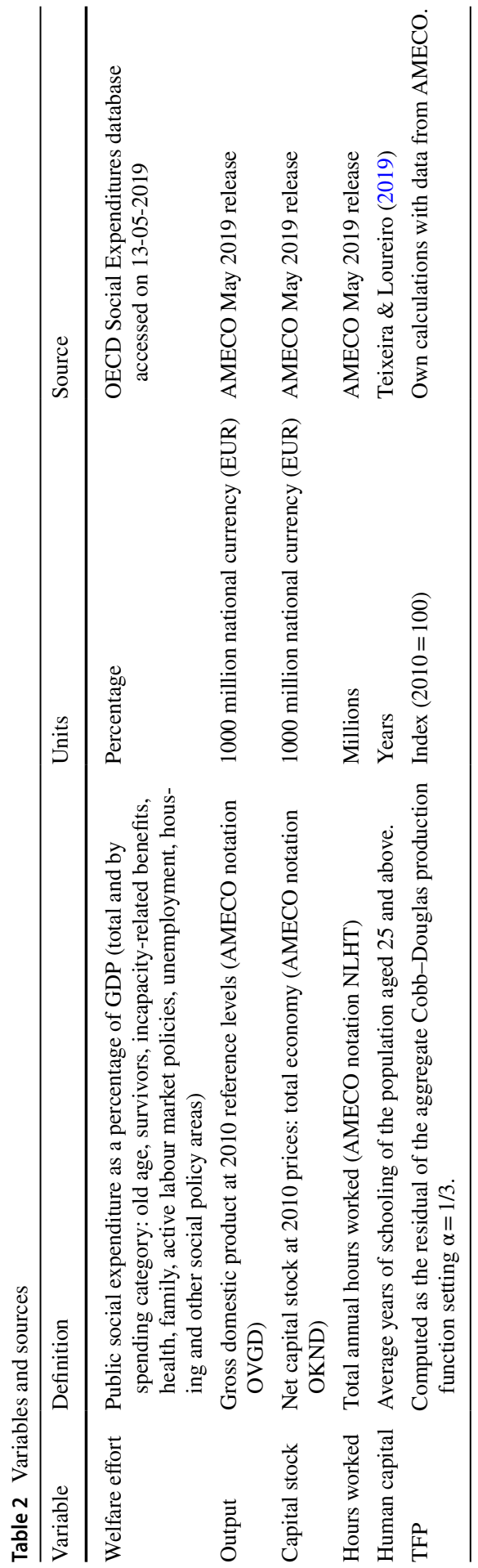



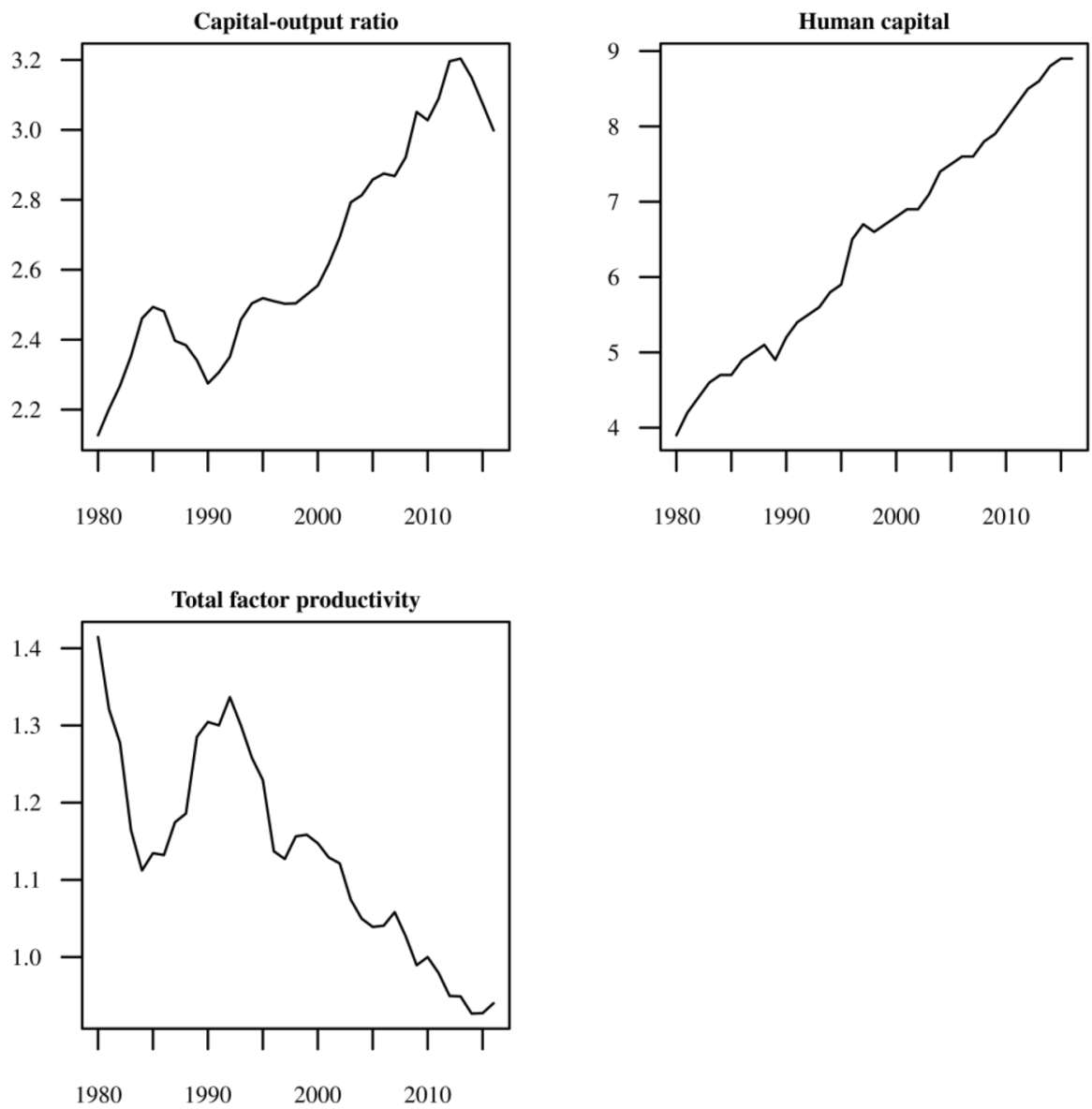

Fig. 3 Aggregate production function variables in levels

of the parameter of interest. In this paper, we define the parameter of interest (the quantity to be estimated in order to gauge the impact of welfare state expenditure on economic growth) to be the long-term impact of a permanent shock to the level of welfare state expenditure (as a percentage of GDP) on the level of output (in logarithms). A recent line of research (e.g. Baek and Lee 2020) has drawn attention to the fact that dynamic single equation models may give misleading results concerning the impulse-response function at a longer horizon than the number of lags in the model. The starting point of that line of research is the assumption that the approximation encapsulated in the model leaves out terms that are non-negligible for the intended analysis. The starting point in our paper, as in many other papers-for example, those following the lead of Blanchard and Quah (1989) — is that the VAR approximation is good enough for the intended analysis, even when long-run restrictions are the object of study. 

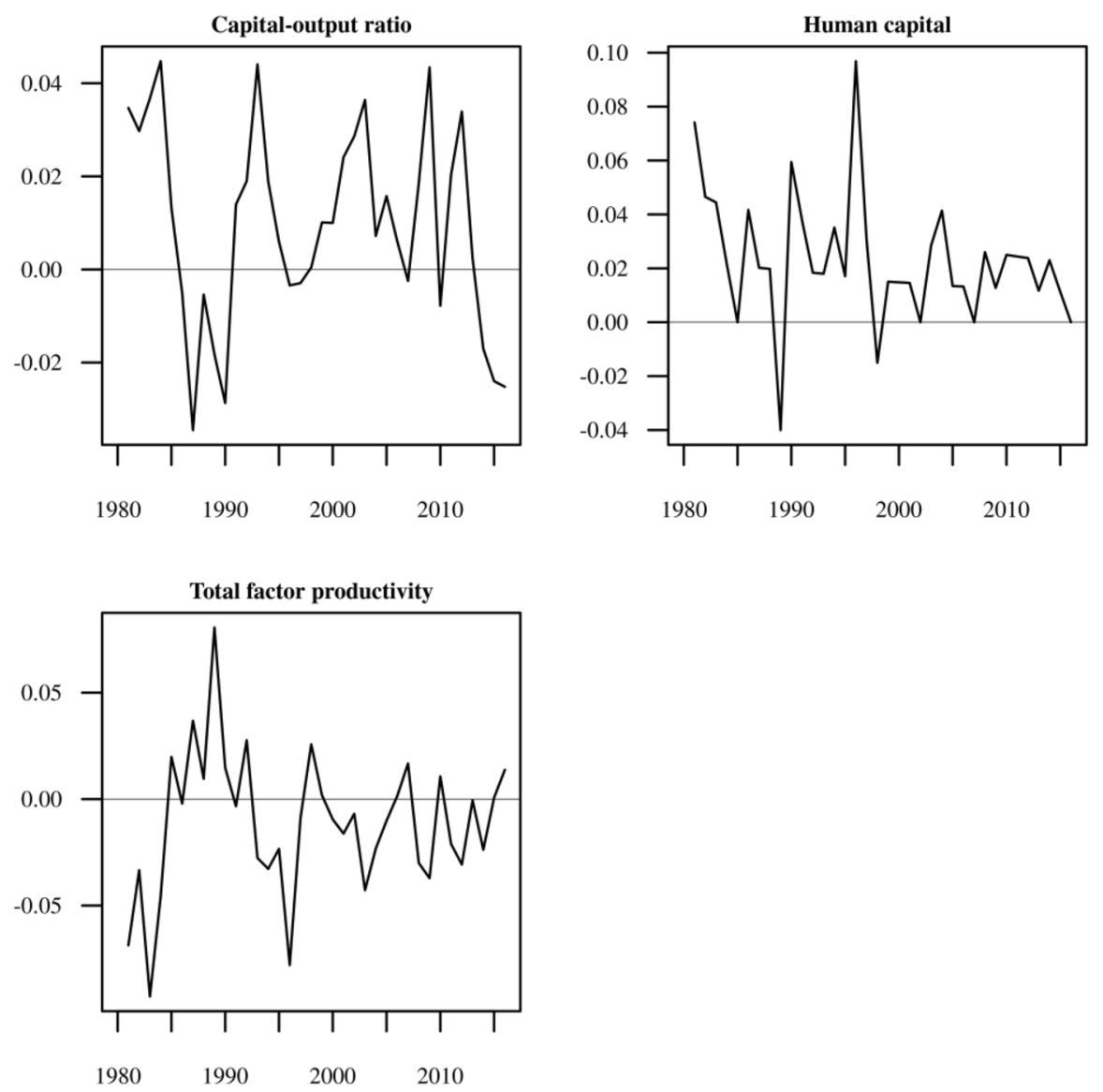

Fig. 4 Aggregate production function variables in annual log growth rates

We approximate the long-term impact by examining the impact after 100 periods. The impact will be measured by the impulse-response function, aggregated according to Eq. (4) to obtain the impact on output. Recall that output is not included in the VAR model. In fact, Eq. (4) shows that it would be exactly collinear with the growth rates of human capital, the capital-output ratio and TFP. We use the standard Cholesky decomposition to estimate the impulse-response functions. Since the results obtained using the Cholesky decomposition depend on the ordering of the variables in the VAR model (see Christiano et al. 1999) and there is no obvious ordering, there is an additional degree of freedom available to the researcher. Nevertheless, we will restrict the orderings so that $g_{t}^{K / Y}$ always comes last, that is to say, it responds faster to shocks than the other variables in the model. The reason for this assumption is that this variable depends on output and output depends on the other variables in the model (except, possibly, welfare state spending, which is the hypothesis we wish to test). 
Given the number of choices that the researcher must make, it is possible that two researchers working on the same dataset but using two different sets of modelling choices will arrive at different conclusions. Often, each researcher will present the main econometric results alongside robustness checks. However, the robustness checks will typically correspond to only a small fraction of all the choices available to the researcher. Inspired by the "reproducibility crisis" in psychology, Steegen et al. (2016) suggested instead the use of a "multiverse analysis". This consists in identifying all the choices made in processing the data and redoing the statistical analysis under all the possible alternatives (which produces a "data multiverse"). The result will be a set of results obtained under different data processing choices. One can then check whether the result reported by the researcher is specific to the choices made by that researcher or whether it is indeed robust.

Simonsohn et al. (2015) go even further and propose a "specification-curve analysis". The first step in this analysis is similar to the multiverse analysis: estimate the parameter of interest under all reasonable alternative specifications. By doing this, one obtains a curve with the estimates derived from the alternative specifications. In the second step, Simonsohn et al. (2015) suggest that one builds simulated datasets in which the null hypothesis concerning the parameter of interest is true. The third step is to estimate the parameter of interest using these simulated datasets under all reasonable alternative specifications. At the end of this step, one has many curves of estimates of the parameter of interest, one curve for each simulation of the dataset under the null hypothesis. The issue then becomes whether, under the null hypothesis, observing a curve such as the one estimated in the first step is likely or not. This likelihood is assessed via the computation of certain statistics for the curve estimated using the actual dataset, and calculation of the share of curves estimated using the simulated datasets that report statistics of similar magnitude. If the values of the statistics corresponding to the observed curve are also frequent in the curves derived from the simulated datasets, then probably the null hypothesis is true.

In this text, we apply the specification-curve analysis to assess the robustness of results concerning the impact of welfare state spending on economic growth in the context of the VAR model described above. Our procedure for constructing the simulated datasets under the null hypothesis of no effect of welfare-spending on economic growth is the following. The VAR model is estimated on the actual dataset (which covers the period 1980-2018 for Portugal) using the preferred (or reference) specification. From this estimation, we obtain an estimate of the variance-covariance matrix of the residuals, say $V$. We apply the Cholesky decomposition to this matrix to obtain a matrix $S$ such that $S S^{\prime}=V$. With $S$ and the residuals of the VAR model, we can compute an estimate of the underlying structural shocks. We create a modified $S$ matrix such that the structural shock associated with welfare spending does not affect the other variables contemporaneously. We use the modified $S$ matrix to compute modified residuals which conform to that restriction. We also modify the estimated matrix of coefficients of the VAR model - the betas in Eq. (6) - so that lagged welfare spending does not affect the other variables. Note that we are in effect imposing no short-run, as well as no long-run, impact of welfare spending on output. Allowing for short-run effects while ruling out long-run effects 
Table 3 Modelling choices

\begin{tabular}{|c|c|}
\hline Decision & Options \\
\hline Which measure of welfare state spending? & $\begin{array}{l}\text { Sum of any subset of the following: old age pen- } \\
\text { sions, survivors' pensions, incapacity related, } \\
\text { health, family allowances, unemployment benefits } \\
\text { and other social policy areas* }\end{array}$ \\
\hline $\begin{array}{l}\text { Take the logarithm of the measure of welfare state } \\
\text { spending? }\end{array}$ & Yes or No \\
\hline $\begin{array}{l}\text { Take the first difference of the measure of welfare } \\
\text { state spending? }\end{array}$ & Yes or No \\
\hline How many lags should the VAR model include? & $\begin{array}{l}1 \text { or } 2 \text { (given the number of observations, inclusion } \\
\text { of longer lags is not desirable) }\end{array}$ \\
\hline $\begin{array}{l}\text { What should be the ordering of the variables in the } \\
\text { VAR model? }\end{array}$ & $\begin{array}{l}\text { Four combinations: welfare state spending in posi- } \\
\text { tion } 2 \text { with human capital and TFP alternating } \\
\text { in positions } 1 \text { and } 3 \text {; welfare state spending in } \\
\text { position } 1 \text {; welfare state spending in position } 3 \text {. In } \\
\text { the last two cases, the ordering of human capital } \\
\text { and TFP is indifferent. The capital-output ratio } \\
\text { always comes last. }\end{array}$ \\
\hline
\end{tabular}

*Education expenditure is not considered due to lack of data for the years 1997 and 1998 and because it is not included in total public social expenditure in the OECD SOCX database. Housing and active labour market policies expenditures take on very small values and therefore were included in the category of other social policy areas

would require complex procedures that would make harder to apply the large-scale approach involved in the specification-curve analysis.

Given the modified residuals and the modified matrix of coefficients, we generate alternative datasets (in which the null of no impact of welfare spending on growth is imposed) by bootstrapping the modified residuals and using them to feed the VAR model. As in Simonsohn et al. (2015), we construct 500 alternative datasets. The modelling choices are listed in Table 3. They give rise to a total of 4064 alternative specifications, which are applied to each of the 500 simulated datasets, besides being applied to the original dataset.

\section{Results}

As per the roadmap set out in the previous section, we begin by estimating the impact of welfare spending on output using the original dataset for all possible combinations of the modelling choices listed in Table 3. The estimates are reported in Fig. 5, ordered by ascending value. A minority of extremely large negative estimates dominate the plot, obscuring the behaviour of the rest of the estimates.

Given the modelling choices, what estimate would a researcher probably arrive at? If the researcher focuses on finding estimates derived from a VAR model in which lags of the welfare spending variable are statistically significant in the equations of the other variables-i.e. welfare spending Granger-causes at least one of the other variables - then the researcher would end up with one of 152 possible 


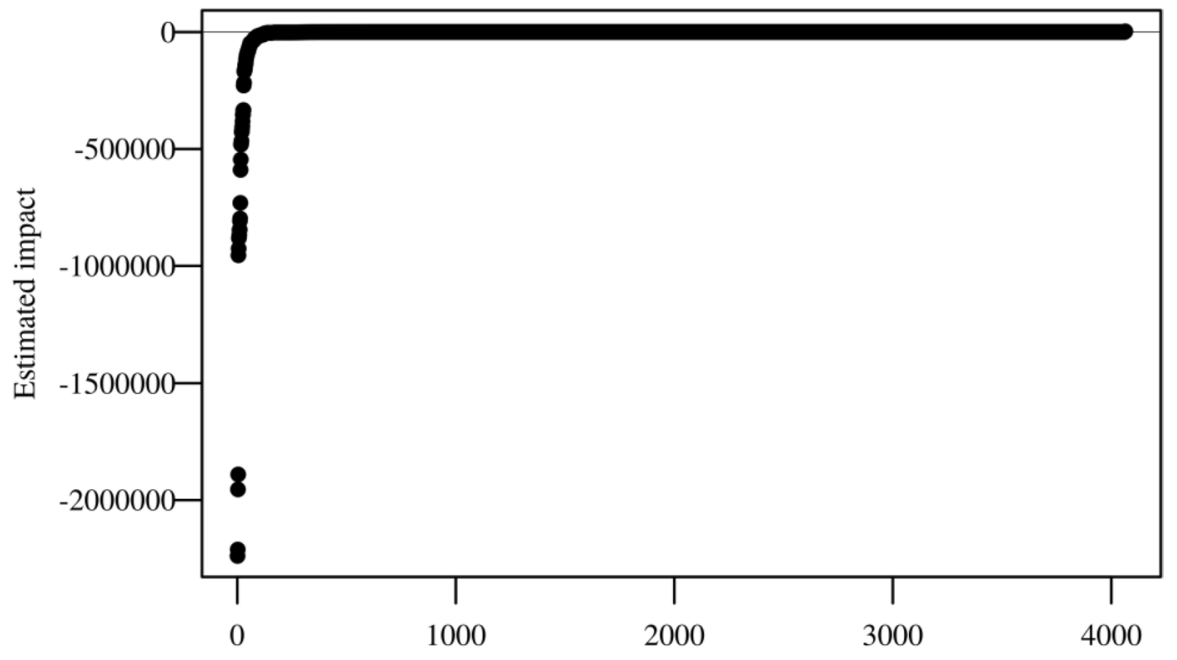

Rank of the estimate when sorted in ascending order

Fig. 5 Estimates of the impact of welfare state spending on output. Notes: The estimates are ordered by ascending value. The estimates concern the long-run impact on output of a unit increase in the measure of social spending. Source: authors' computations

specifications that reject the null hypothesis of no Granger causality for at least one of the other variables, at a significance level no larger than 10 per cent. ${ }^{3}$ In most of those 152 specifications, either the largest component of social expenditure (old age pensions) or the smallest components (grouped in "other social policy areas"recall Table 3) appear. If the researcher decides to focus on old age pensions, then there are 64 specifications in which it appears (sometimes on its own, other times summed with other elements) and in which welfare spending Granger-causes at least one of the other variables. Narrowing further to those specifications in which welfare spending is measured by old age pensions alone-a natural focus point, given the concerns that problems caused by ageing populations have been raising recently-there are only four specifications at which the researcher might arrive. Those specifications differ only in the ordering of the variables in the VAR model. In all of them, the researcher would take the logarithm of old age pensions, firstdifference it and estimate a VAR model with one lag. The corresponding estimates are reported in Table 4.

\footnotetext{
3 To choose the number of lags in the VAR model, the researcher could use information criteria such as the Akaike information criterion, Schwarz's Bayesian information criterion, or the Hannan-Quinn information criterion. The approach used in this paper, which included the Granger causality tests (very popular in applied econometrics), led to specifications where the number of lags is always one. Therefore, we feel that for our present purposes it is unnecessary to use information criteria, which would introduce another choice (the choice of the information criterion to use) and increase the number of specifications under analysis. In addition, in a short sample such as ours, using information criteria of an asymptotic nature may not be desirable.
} 
Table 4 Estimates of the impact of welfare spending (old age pensions) on output

\begin{tabular}{llllr}
\hline Ordering & & & Estimate \\
\hline Human capital & TFP & Welfare & Capital-output & 0.041 \\
Human capital & Welfare & TFP & Capital-output & -0.285 \\
TFP & Welfare & Human capital & Capital-output & 0.016 \\
Welfare & Human capital & TFP & Capital-output & -0.347 \\
\hline
\end{tabular}

Estimates obtained when the welfare variable in the VAR model is the first difference of the logarithm of old age pensions, and the VAR model includes only one lag

Interestingly, the sign of the estimate varies with the ordering of the variables in the VAR model. This is the point at which the researcher's preconceptions (ideology) might come into play and tip the choice of the model to report in the research paper into one direction or the other. Let us suppose that the researcher decides to employ the first ordering, either because of preconceptions or because the researcher believes this model provides a better fit to the data. The researcher then reports that, if welfare spending goes up by one percentage point, output will increase by 0.04 percentage points in the long run. The researcher also reports that this result comes from a VAR model in which welfare spending Granger-causes at least one of the other variables, lending credence to the conclusion that welfare spending influences output (in this case, positively).

What does specification-curve analysis tell us about the robustness of this conclusion? Assuming that the VAR model chosen is correct, we need to construct the alternative datasets imposing the null hypothesis of no impact of welfare spending on the other variables, as detailed in the previous section. We then need to estimate the 4064 specifications on those 500 datasets. Figure 6 shows the 2.5 and the 97.5 percentiles for each specification, as well as the estimates obtained under each specification using the original data (black dots). Note that percentile curves were obtained by smoothing the actual percentiles. Also note that now the specifications are ordered from the specification with the lowest amplitude (difference between the 97.5 and 2.5 percentiles) to the specification with the highest amplitude (instead of from the specification that yields the lowest estimate to the specification that yields the highest estimate, as was the case in Fig. 5).

Figure 6 suggests that the estimates obtained with the original dataset do not differ much from the estimates obtained assuming that in the original dataset welfare spending has a positive impact on output and estimating the impact with simulated datasets in which that impact is eliminated. Figure 7 provides the same kind of results for the case where the researcher chooses the fourth ordering in Table 5 and reports a negative impact of welfare spending on output.

As we mentioned in the previous section, the figures provide an impression of the similarity (or dissimilarity) between the estimates from the actual dataset and the estimates from the simulated datasets. However, one should quantify the degree of similarity by computing statistics on the two sets of results. Table 5 provides this quantification along four dimensions. First, we compute the percentage of simulations in which the median estimate across the specifications is at least as large (when 

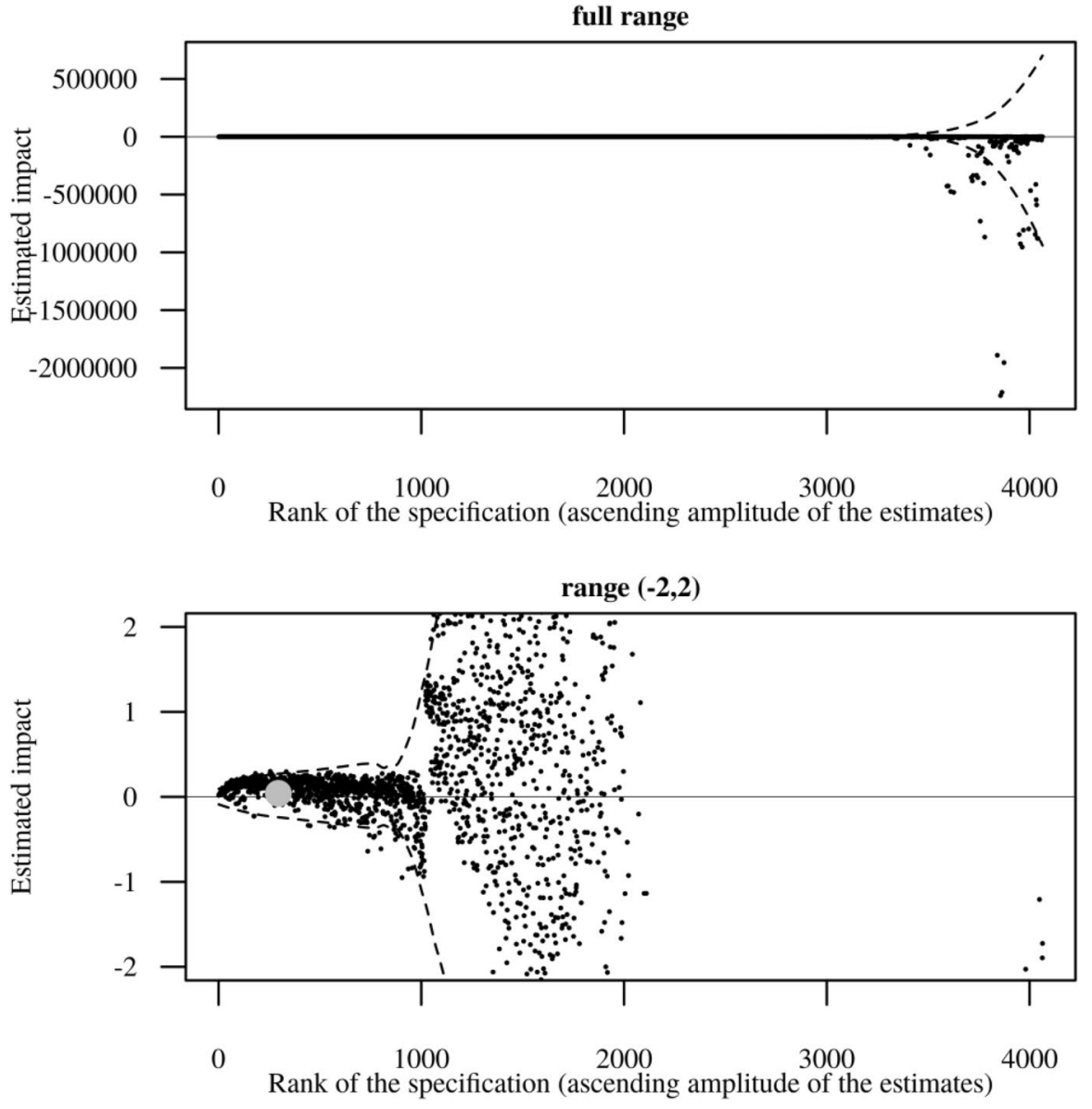

Fig. 6 Specification-curve analysis under assumed positive impact. Notes: The specifications are ordered by ascending amplitude of the estimates in the simulations. The grey dot corresponds to the matching estimate in Table 5 (first ordering of the variables). Source: authors' computations

analysing the robustness of the positive estimate; "as small" in the case of the negative estimate) as in the estimates on the actual dataset (where the median is -3.85). Then we compute the percentage of simulations in which the share of positive (negative) estimates across the simulations is at least as large as in the estimates on the actual dataset (positive: 1428/4064; negative 2636/4064). Thirdly, we do the same but restricting to positive (negative) estimates that are statistically significant (positive: 105/4064; negative: 47/4064). Finally, we compute the percentage of simulations in which the share of estimates across the simulations that is above (below) the 97.5 (2.5) percentile is at least as large as in the estimates on the actual dataset (positive: 26/4064; negative: 21/4064). These numbers suggest that the observed positive estimate of the impact of welfare spending on output, although based on a VAR model in which the tests indicate Granger causality from welfare spending to 

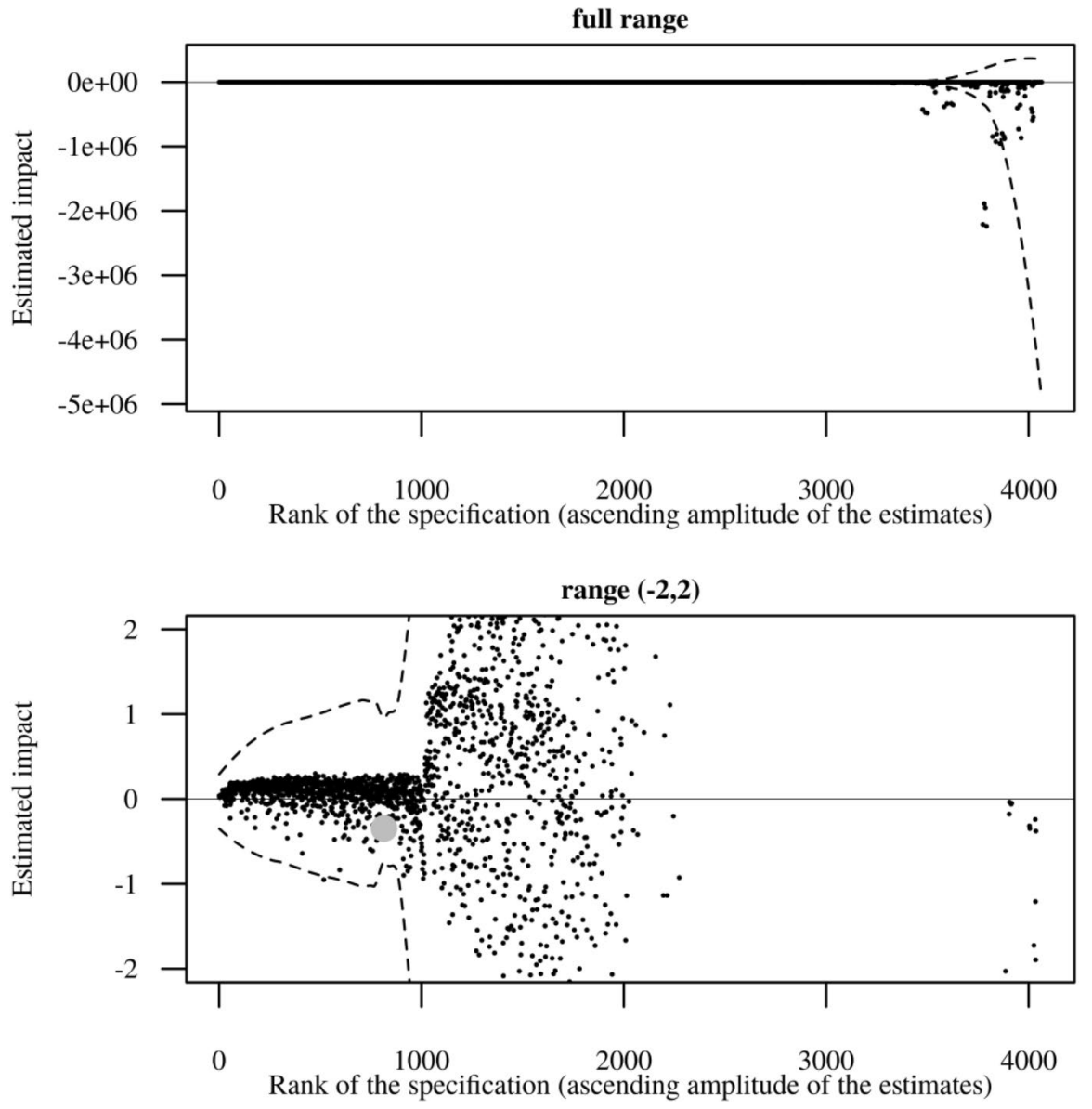

Fig. 7 Specification-curve analysis under assumed negative impact. Notes: The specifications are ordered by ascending amplitude of the estimates in the simulations. The grey dot corresponds to the matching estimate in Table 5 (last ordering of the variables). Source: authors' computations

Table 5 Indicators for specification-curve analysis

\begin{tabular}{lcc}
\hline Indicators & Positive & Negative \\
\hline Median at least as large (small) & 0.918 & 0.502 \\
Share of positive (negative) estimates at least as large & 0.678 & 0.570 \\
Share of statistically significant positive (negative) estimates at least as large & 0.654 & 0.920 \\
Share of estimates above (below) the 97.5 (2.5) percentile at least as large & 0.400 & 0.462 \\
\hline
\end{tabular}

output, is compatible with the null hypothesis of no impact being true: the percentage of cases in the simulations in which the same magnitudes of the statistics are attained is very high. The same can be said about the observed negative estimate. 
Therefore, the conclusion seems to be that, with our dataset and the specifications employed, the impact of welfare spending on growth is indistinguishable from zero, in the sense that specifications that produce statistically significant estimates of this impact fail the robustness check provided by specification-curve analysis.

\section{Conclusion}

We looked at the relationship between the welfare state and economic growth in Portugal over the period 1980-2018. This period coincides with the early years and deepening of the European integration process by Portugal, involving also transformations in the welfare state system in this country. Those transformations are the basis for the current social rights and organizational structure that provides welfare in Portugal and made it converge to the European Social Model. The possibility that welfare state retrenchment resulting from the recent sovereign debt crises has a negative impact on economic growth is an important question worthy of rigorous empirical testing. Our focus has been on the influence of public social expenditure on output growth through factor accumulation and total factor productivity, considering also the impact of different social spending categories. For this purpose, we estimated a VAR model based on a standard aggregate Cobb-Douglas production function.

A problem that characterizes empirical analyses is that there are usually different ways of testing a relation and researchers tend to report only a subset of results, driven by particular choices and very often a desire for statistically significant results, what Rohrer (2018) calls the "researcher degrees of freedom trap". To overcome to some extent this problem and contribute to the transparency and robustness of the results on the link between the welfare state and economic growth, we applied specification-curve analysis (SCA), proposed by Simonsohn et al. (2015), to our VAR model. SCA broadly consists of specifying and running all reasonable models with the actual data and then comparing the results obtained with a simulated dataset where the null hypothesis of no effect is the true one. We defined the parameter of interest to be the long-term impact of a permanent shock to the level of welfare state expenditure on the level of output. The modelling choices give rise to a total of 4064 alternative specifications, which were applied to 500 simulated datasets as well as to the original dataset.

The results suggest that the estimates obtained with the original dataset do not differ much from the estimates obtained on simulated datasets in which the true impact is null. In fact, we computed statistics on the two sets of results to quantify the degree of similarity and the numbers suggest that the observed positive (negative) estimate of the impact of welfare state spending on output, is compatible with the null hypothesis of no impact being true.

From a macroeconomic performance perspective, our findings thus do not endorse increasing welfare spending as a means to increase output in Portugal over the long run. Our analysis, however, does not provide a definite answer to whether social spending impacts economic growth in Portugal: the specification-curve 
analysis indicates that the statistically significant results found are not robust. We used a VAR model defined according to a Cobb-Douglas production function to identify the long-run impact of social spending on output through factor accumulation and productivity. Alternative approaches include: considering different types of production functions; considering alternative modelling approaches; or accommodating the potential for a nonlinear relationship. Due to the large-scale approach involved in the specification-curve analysis we imposed both no short-run as well as no long-run impact of welfare state spending on output to obtain the simulated datasets. Allowing for short-run effects while ruling out long-run effects would require complex procedures that would make harder to apply specification-curve analysis. Our aim was to implement the most robust analysis of the research question posed in this study, "Is the welfare state relevant for economic growth?" but there are also issues intrinsic to the data that may constitute important limitations. First, the use of social spending alone as a measure of the welfare state is not problem free. The impact on economic growth might depend also on the financing schemes and organizational structure of the welfare system. Second, carrying out a time series econometric analysis with a short data coverage might hamper the robustness of the results. Finally, the behaviour of some of the series used in the analysis, such as the physical capital series, may have a detrimental impact on the performance of our VAR model.

Acknowledgements The authors are very grateful for the comments received from two anonymous referees and to the Editor of the Special Issue, Andreea Stoian.

Funding Funding was provided by COMPETE 2020, Portugal 2020 and the European Union through FEDER; and national funds were provided by Fundação para a Ciência e a Tecnologia I.P./MCTES (Grant No. POCI-01-0145-FEDER-029365; PTDC/EGE-ECO/29365/2017).

\section{References}

Acosta-Ormaechea, S., and J. Yoo. 2012. Tax Composition and Growth: A Broad Cross-country. Perspective. IMF Working Papers No. 12/257.

Afonso, A., and J.G. Alegre. 2011. Economic Growth and Budgetary Components: A Panel Assessment for the EU. Empirical Economics 41: 703-723.

Afonso, A., and D. Furceri. 2010. Government Size, Composition, Volatility and Economic Growth. European Journal of Political Economy 26(4): 517-532.

Afonso, António, and J.T. Jalles. 2014. Fiscal Composition and Long-Term Growth. Applied Economics 46(3): 349-358.

Aghion, P., E. Caroli, and C. García-Peñalosa. 1999. Inequality and Economic Growth: The Perspective of the New Growth Theories. Journal of Economic Literature 37: 1615-1660.

Andersen, T. 2015. The Welfare State and Economic Performance: Appendix 4 to the Long-Term Study of Sweden 2015 by the Swedish Ministry of Finance, No. SOU 2015: 53.

Arjona, R., M. Ladaique, and M. Pearson. 2002. Social Protection and Growth. OECD Economic Studies 35(2): 7-45.

Arnold, J., B. Brys, C. Heady, A. Johansson, C. Schwellnus, and L. Vartia. 2011. Tax Policy for Economic Recovery and Growth. Economic Journal 121(550): F59-F80.

Atkinson, A.B. 1995. Is the Welfare State Necessarily an Obstacle to Economic Growth? European Economic Review 39(3-4): 723-730. 
Atkinson, A.B. 1996a. Growth and the Welfare State: Is the Welfare State Necessarily Bad for Economic Growth? New Economy 3(3): 182-186. https://doi.org/10.1111/j.1468-0041.1996.tb00140.x.

Atkinson, A. 1996b. The Economics of the Welfare State. The American Economist 40(2): 5-15.

Awaworyi Churchill, S., S.L. Yew, and M. Ugur. 2015. Effects of Government Education and Health Expenditures on Economic Growth: A Meta-analysis. SSRN Electronic Journal. https://doi. org/10.2139/ssrn.2693942.

Awaworyi Churchill, S., M. Ugur, and S.L. Yew. 2017. Government education expenditures and economic growth: a meta-analysis. The B.E. Journal of Macroeconomics 17(2): 1.

Awaworyi Churchill, S., and S.L. Yew. 2017. Are government transfers harmful to economic growth? A meta-analysis. Economic Modelling 64(C): 270-287.

Baek, C.W., and B. Lee. 2020. A Guide to Single Equation Regressions for Impulse Response Estimations. https://drive.google.com/file/d/1JcErFrQsVP1INgJeulhhonqthzZsCJmx/view. Accessed May $12,2020$.

Baldacci, E., B. Clements, S. Gupta, and Q. Cui. 2008. Social Spending, Human Capital, and Growth in Developing Countries. World Development 36(8): 1317-1341.

Barro, R., and J.-W. Lee. 2013. A New Data Set of Educational Attainment in the World, 1950-2010. Journal of Development Economics 104(C): 184-198.

Benos, N., and S. Zotou. 2014. Education and Economic Growth: A Meta-Regression Analysis. World Development 64(C): 669-689.

Berg, A., J. Ostry, C. Tsangarides, and Y. Yakhshilikov. 2018. Redistribution, inequality, and growth: new evidence. Journal of Economic Growth 23(3): 259-305.

Bergqvist, K., M. Yngwe, and O. Lundberg. 2013. Understanding the Role of Welfare State Characteristics for Health and Inequalities-An Analytical Review. BMC Public Health 13: 1234.

Bijlsma, M., J. Bonekamp, C. Van Ewijk, and F. Haaijen. 2018. Funded Pensions and Economic Growth. De Economist 166(3): 337-362.

Blanchard, O.J., and D. Quah. 1989. The Dynamic Effects of Aggregate Demand and Supply Disturbances. American Economic Review 79(4): 655-673.

Bloom, D.E., M. Kuhn, and K. Prettner. 2018. Health and Economic Growth. IZA Discussion Papers No 11939.

Brock, W., and S. Durlauf. 2001. Growth Empirics and Reality. World Bank Economic Review 15: 229-272.

Brown, E., and H. Kaufold. 1988. Human Capital Accumulation and the Optimal Level of Unemployment Insurance Provision. Journal of Labour Economics 6(4): 493-514.

Bryan, C.J., D.S. Yeager, and J.M. O’Brien. 2019. Replicator Degrees of Freedom Allow Publication of Misleading Failures to Replicate. Proceedings of the National Academy of Sciences 116(51): 25535-25545

Caminada, K., K. Goudswaard, C. Wang, and J. Wang. 2019. Income Inequality and Fiscal Redistribution in 31 Countries After the Crisis. Comparative Economic Studies 61(1): 119-148.

Carolo, D.F., and J. Pereirinha. 2010. The development of the Welfare State in Portugal: trends in social expenditure between 1938 and 2003. Revista de História Económica 28(03): 469-501.

Chauvel, L., and E. Bar-Haim. 2016. Varieties of Capitalism (VoC) and Varieties of Distributions (VoD): How Welfare Regimes Affect the Pre- and Post-Transfer Shapes of Inequalities? LIS Working Papers No. 677.

Christiano, L.J., M. Eichenbaum, and C.L. Evans. 1999. Monetary Policy Shocks: What Have We Learned and to What End? In Handbook of Macroeconomics, vol. 1A, ed. J.B. Taylor and M. Woodford. Amsterdam: Elsevier.

Chu, Tuan T., Jens Hölscher, and Dermot McCarthy. 2018. The Impact of Productive and Non-Productive Government Expenditure on Economic Growth: An Empirical Analysis in High-Income Versus Low- to Middle-Income Economies. Empirical Economics 58: 2403-2430.

Cingano, F. 2014. Trends in Income Inequality and its Impact on Economic Growth. OECD Social, Employment and Migration Working Papers No 163.

Cingano, Federico. 2014. Trends in Income Inequality and Its Impact on Economic Growth. OECD Economics Department Working Papers No. 163.

Dominicis, L.D., R.J.G.M. Florax, and H.L.F. De Groot. 2008. A Meta-Analysis on the Relationship between Income Inequality and Economic Growth. Scottish Journal of Political Economy 55(5): 654-682.

Esping-Andersen, G.T. 1990. The Three Worlds of Welfare Capitalism. Princeton, New Jersey: Princeton University Press. 
Fournier, J.-M., and A. Johansson. 2016. The Effect of the Size and the Mix of Public Spending on Growth and Inequality. OECD Economics Department Working Papers No. 1344.

Frey, R., D. Richter, J. Schupp, R. Hertwig, and R. Mata. 2020. Identifying Robust Correlates of Risk Preference: A Systematic Approach Using Specification Curve Analysis. Journal of Personality and Social Psychology. https://doi.org/10.1037/pspp0000287.

Furceri, D., P. Loungani, J. Ostry, and P. Pizzuto. 2020. Financial Globalization, Fiscal Policies and the Distribution of Income. Comparative Economic Studies 62(2): 185-199.

Galor, O., and O. Moav. 2004. From Physical to Human Capital Accumulation: Inequality and the Process of Development. Review of Economic Studies 71 (4): 1001-1026.

Gonzalez, P., and A. Figueiredo. 2015. The European Social Model in a Context of Crisis and Austerity in Portugal. In The European Social Model in Crisis. Is Europe Losing Its Soul? (Chapter 8), ed. D. Vaughan-Whitehead, 386-450. Cheltenham: Edward Elgar.

Hall, R.E., and C. Jones. 1999. Why do Some Countries Produce So Much More Output Per Worker than Others? The Quarterly Journal of Economics 114(1): 83-116.

Hay, C., and D. Wincott. 2012. The Political Economy of European Welfare Capitalism. Basingstoke: Palgrave Macmillan.

Herce, J.A., S. Sosvilla-Rivero, and J.J. de Lucio. 2001. Growth and the Welfare State in the EU: A Causality Analysis. Public Choice 109: 55-68.

Im, T., W. Cho, and G. Porumbescu. 2011. An Empirical Analysis of the Relation between Social Spending and Economic Growth in Developing Countries and OECD Members. The Asia Pacific Journal of Public Administration 33: 37-55.

Johansson, A., Christopher Heady, Jens Arnold, Bert Brys, and Laura Vartia. 2008. Taxation and Economic Growth. OECD Economics Department Working Papers No. 620.

Johansson, A. 2016. Public Finance, Economic Growth and Inequality: A Survey of the Evidence. $O E C D$ Economics Department Working Papers No. 1346.

Kammer, A., J. Niehues, and A. Peichl. 2012. Welfare Regimes and Welfare State Outcomes in Europe. Journal of European Social Policy 22(5): 455-471.

Kim, K., and R. Antonopoulos. 2011. Unpaid and Paid Care: The Effects of Child Care and Elder Care on the Standard of Living. Working Paper. Levy Economics Institute No. 691.

Lindert, P. 2004. Growing Public: Social Spending and Economic Growth since the Eighteenth Century. Cambridge: Cambridge University Press.

McNabb, Kyle. 2018. Tax Structures and Economic Growth: New Evidence from the Government Revenue Dataset. Journal of International Development 30(2): 173-205.

Nolan, B., Wiemer Salverda, Timothy M. Smeeding, Gøsta Esping-Andersen, and John Myles. 2012. Economic Inequality and the Welfare State. Oxford University Press.

OECD. 2019. The OECD SOCX Manual 2019 Edition-A Guide to the OECD Social Expenditure Database. Paris: OECD.

Orben, A., and A.K. Przybylski. 2019. The Association Between Adolescent Well-Being and Digital Technology Use. Nature Human Behaviour 3(2): 173-182.

Ormaechea, S. A., and A. Morozumi. 2013. Can a Government Enhance Long-Run Growth by Changing the Composition of Public Expenditure? IMF Working Papers No. 13/162.

Pfaller, A. 1987. Are the Western Welfare States Still Competitive? Intereconomics 22(3): 112-119.

Piachaud, D. 2013. Social Protection, Redistribution and Economic Growth. Development Southern Africa 30(1): 24-38.

Prichard, W. 2016. Reassessing Tax and Development Research: A New Dataset, New Findings, and Lessons for Research. World Development 80: 48-60.

Rockey, James, and Jonathan Temple. 2016. Growth Econometrics for Agnostics and True Believers. European Economic Review 81: 86-102.

Rodrik, D. 2003. In Search of Prosperity: Analytic Narratives on Economic Growth. Princeton: Princeton University Press.

Rohrer, J. 2018. Run All the Models! Dealing With Data Analytic Flexibility. Observer 31(3): 25-27.

Rohrer, J., B. Egloff, and S. Schmukle. 2017. Probing Birth-Order Effects on Narrow Traits Using Specification-Curve Analysis. Psychological Science 28(12): 1821-1832.

Romer, C.D., and D.H. Romer. 2016. Transfer Payments and the Macroeconomy: The Effects of Social Security Benefit Changes, 1952-1991. American Economic Journal: Macroeconomics 8(4): 1-42.

Simonsohn, U., J.P. Simmons, and L.D. Nelson. 2015. Specification curve: Descriptive and inferential statistics on all reasonable specifications. Retrieved from http://urisohn.com/. Accessed 1 July 2019. 
Steegen, S., F. Tuerlinckx, A. Gelman, and W. Vanpaemel. 2016. Increasing transparency through a multiverse analysis. Perspectives on Psychological Science 11(5): 702-712.

Stiglitz, Joseph E. 2018. The Welfare State in the Twenty-First Century. In The Welfare State Revisited (chapter 1), ed. J.A. Ocampo and J.E. Stiglitz. New York: Columbia University Press.

Teixeira, A.A.C., and A.S. Loureiro. 2019. FDI, income inequality and poverty: a time series analysis of Portugal, 1973-2016. Portuguese Economic Journal 18(3): 203-249. https://doi.org/10.1007/s1025 8-018-00152-x.

Toikko, T., and T. Rantanen. 2017. How Does the Welfare State Model Influence Social Political Attitudes? An Analysis of Citizens' Concrete and Abstract Attitudes toward Poverty. Journal of International and Comparative Social Policy 33(3): 201-224.

Tridico, P., and W. Paternesi Meloni. 2018. Economic growth, welfare models and inequality in the context of globalisation. The Economic and Labour Relations Review 29(1): 118-139.

Van Lancker, W., and A. Van den Heede. 2019. Economic Equality and the Welfare State. SPSW Working Paper, CESO/SPSW/2019-2. Leuven: Centre for Sociological Research, KU Leuven.

Voracek, M., M. Kossmeier, and U.S. Tran. 2019. Which Data to Meta-Analyze, and How? A Specification-Curve and Multiverse-Analysis Approach to Meta-Analysis. Zeitschrift für Psychologie 227: 64-82.

Voyvoda, E., and E. Yeldan. 2005. IMF Programmes, Fiscal Policy and Growth: Investigation of Macroeconomic Alternatives in an OLG Model of Growth for Turkey. Comparative Economic Studies 47(1): 41-79.

Zhang, W., H. Sun, S. Woodcock, and A.H. Anis. 2017. Valuing Productivity Loss due to Absenteeism: Firm-level Evidence from a Canadian Linked Employer-Employee Survey. Health Economics Review 7 (1): 3.

Publisher's Note Springer Nature remains neutral with regard to jurisdictional claims in published maps and institutional affiliations. 